\title{
Conflicting Factors in the Design of Naturally Ventilated Apartment in Warm Humid Tropics
}

\author{
Putri Melati Dewi, and I Gusti Ngurah Antaryama \\ Department of Architecture, FTSP, Institut Teknologi Sepuluh Nopember (ITS) \\ Jl. Arief Rahman Hakim, Surabaya 60111 \\ E-mail: antaryama@arch.its.ac.id
}

\begin{abstract}
One of the most effective strategies in designing a passive ventilation apartment in the warm humid tropical clime is to maximize airflow in a building. However designing such kind of apartment often contradicts with socio-economic aspects such as land usage, privacy and security. The reason for that is on one hand naturally ventilated apartment means maximizing openings as much as possible, on the other hand middle-upper income class people need high security and privacy. Method used for designing this apartment is Evidence Based Design, which makes use of current best evidence from research and precedent in the topic of thermal comfort and residential buildings. This passive design apartment seeks optimum solution to overcome contradictory aspects of thermal comfort and socio-economy, by integrating the main concept of maximizing airflow and maintaining privacy through architectural elements.
\end{abstract}

Keywords-warm humid tropics, evidence-based design, passive design, apartment

\section{INTRODUCTION}

$\mathrm{D}$ ESIGNING building in the warm humid tropical climate means architect has to battle with high sun radiation and high humidity. This condition leads to the feeling of discomfort for the human body of being hot and sweating because of the heat and humidity. As a result the energy consumption for cooling is very high in the hot and humid tropical region. [1]

When it comes to design low energy building, architect should be able to take into consideration of climate and environmental conditions, in order to achieve optimal thermal comfort inside a building and minimizing usage of mechanical cooling. In the warm humid tropical region one of the most effective strategy to achieve thermal comfort is maximizing the airflow in a building, because the air movement surrounding the human body will release the heat from the body through convection and evaporation.[2]

The concept of Wind Tunnel Apartment is proposed based on the strategy of maximizing the airflow in a building. This apartment is intended for middle-upper class people because this economic range groups tends to use air conditioner in their home and nowadays the available apartments in Surabaya are mostly designed with the usage of air conditioners. [3]

The concept of maximizing the airflow is attained by arranging the apartment units in some distance that the air can flow easily through the building, and each of the apartment units are equipped with many openings or windows to optimize the indoor air movement. As a result,

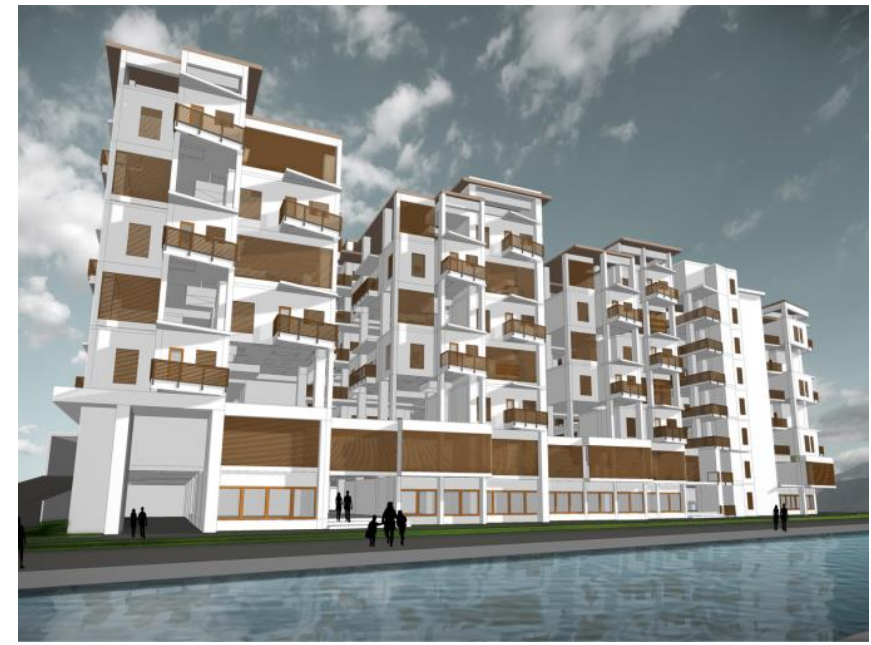

Figure 1. South Perspective of the Apartment

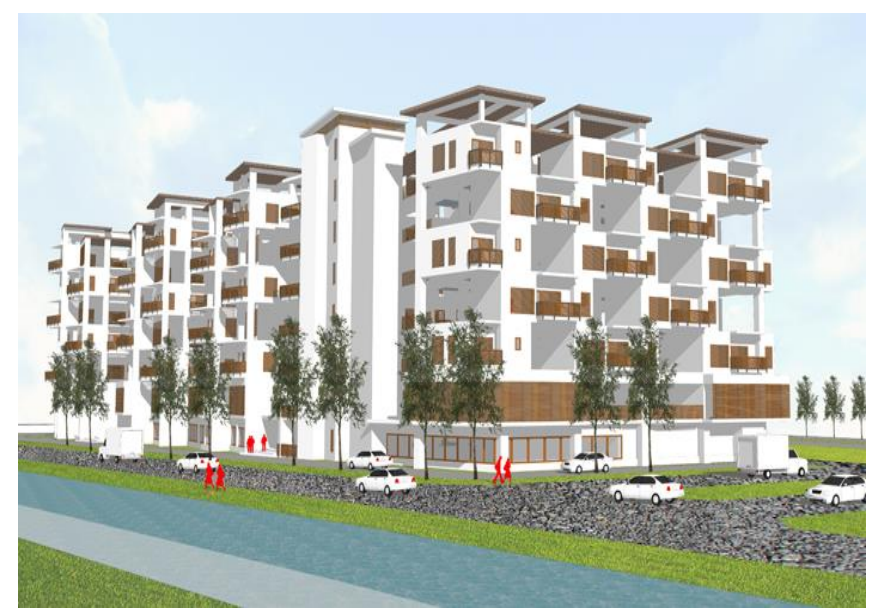

Figure 2. South West Perspective of the Apartment 
the design of Wind Tunnel Apartment shows different architectural expression due to the chessboard-like pattern gaps in the apartment block design.

The main design problem is not solely about the environmental condition of a given place but also about the socio-economic aspects of the occupants. It is the task of this apartment design to integrate these conflicting factors. Wind Tunnel Apartment offers alternative for middle-upper class people who are get used to live in private enclosed space with air conditioner to live in naturally ventilated apartment, which accommodate their needs, such as privacy, and security.

\section{DESIGN METHOD}

The design method used to design this passive apartment is "Evidence Based Design", which makes use of current best evidence from research and practice in making critical decision. These researches and precedents are taken from studies of thermal comfort in a building and residential architecture.

When it comes to design a building which optimize airflow there has to be some criteria that a design has to achieve in order to make effective airflow Basically there are two kinds of airflow, laminar, and turbulent. The laminar flow is more efficient to promote thermal comfort. Therefore to optimize airflow through the building there has to be some distance required between building masses for the wind to transform itself from turbulent into laminar flow again. In this case, if the masses are arranged in the form like chessboard pattern, the distance required is about $2-3 \mathrm{x}$ of building height, as shown in the figure 3.[1]

According to this principle, units in the apartment are arranged like a chessboard pattern. There are two kinds of basic pattern, just like the black and white colour of the chess board pattern. For example, the units in the third floor are placed in the white colour side, and the fourth floor units are placed in the black colour side, arranged overlapping each other, floor by floor as showed by the figure 4 .

In addition, according to the wind data available in the City of Surabaya, most of the time the wind will come from east and west direction. As a result, in the figure $5 \& 6$ of the apertment floor plan, the main pattern of the distance required is in the axes of east and west.

Thermal comfort in this building is not merely rely on the units arrangement that opitimize the wind flow, but also on many architechtural elements from the neoighborhoods level down to the small elements such as window and shading. These strategies are adapted from the book of Sun, Wind, and Light [4]. However still, the main design element to induce air flow inside the building is the openings. For that reason further design exploration is required to accomodate
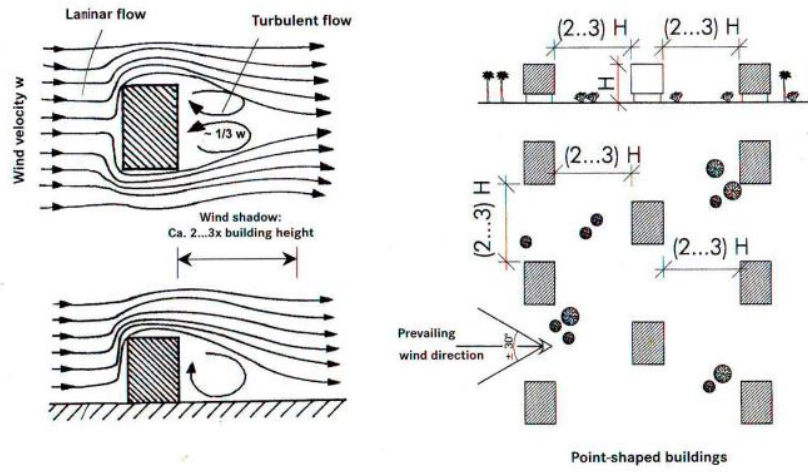

Figure 3. Distance required for the wind flow. Source : Lauber, 2005

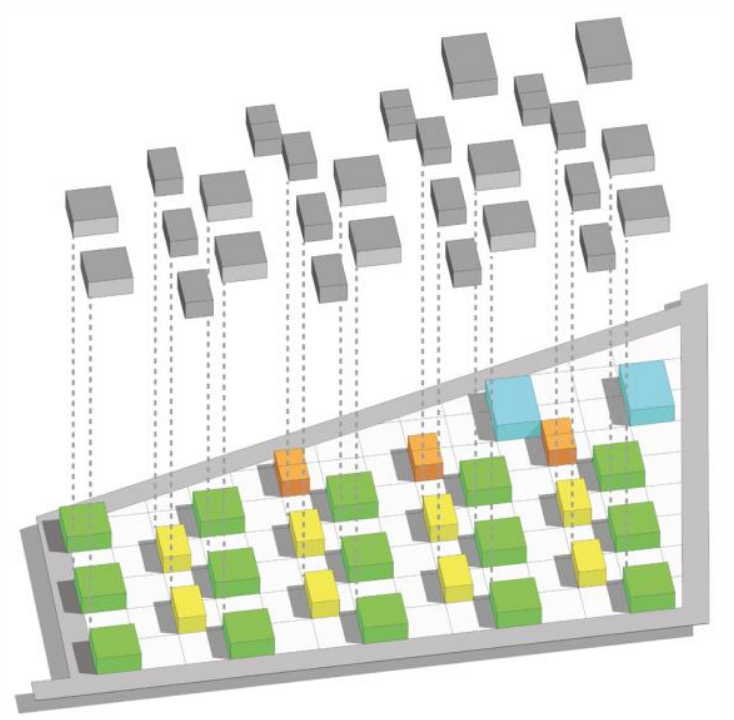

Figure 4. Diagram arrangement of the units

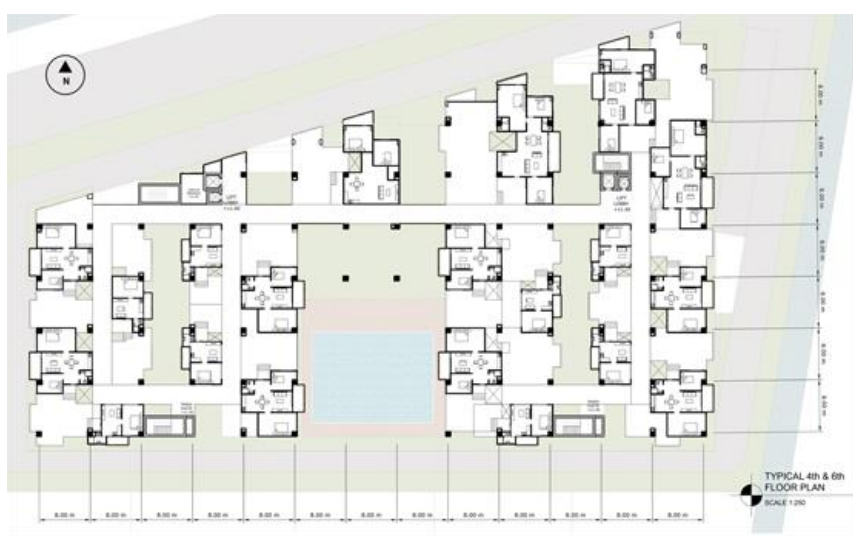

Figure 5. Typical $4^{\text {th }}$ and $6^{\text {th }}$ floor plan

\section{RESULT AND EXPLORATION}

From the design process with the method of Evidence Based Design the whole mass of the Wind Tunnel

Apartment is formed. However further design exploration is required, in order to adapt the design to the social and economy aspects of targeted occupants. the conflicting factors. 
Further exploration of maximizing the airflow is adapted in the internal room layout arrangement. As shown by figure 7 , the apartment unit's layout follows the projected wind direction, thus creating spaces with fewer boundaries inside. The unit's openings are placed on the all side of the walls, making effective cross ventilation system. However apartment unit with many openings are not desirable for the middle-upper people due to the demand of high privacy and security. It is reported from the field survey of natural ventilation in Surabaya, the top reason for not opening windows or door are privacy, insects, and security [3] Therefore the design should be able to encourage the window opening behavior of the occupants.

In order to accommodate both the need of comfort ventilation and privacy, the opening design of this apartment system is explored further. The openings in the apartment are equipped with the 3 layers system, as shown by figure 8 . The outer layer is opening in the form of jalousie or sun louvre, which is useful for shading the entire opening from the sun radiation and also allowing the occupants inside to view outdoor but people outside are unable to see the indoor. The second layer is the insect net to prevent the insects such as mosquito from coming in. The indoor layer is the operable window that can be opened and closed depends on the occupant's behavior.

In addition, the floor level of apartment units are designed higher from the surrounding area to make sure that even though the windows are opened the occupants inside the unit are still in the different level from the people who walk passing by in the corridor. As shown by figure 9, this design strategy will create some distance between public and private space, even though they are next to each other.

The spaces between the apartment units, which is functioned for maximizing the airflow inside the apartment, are functioned as verandah for the units. The concept of adapting the verandah comes from the research by Bay, 2006 in Singapore apartment, Bedok Court that equipped a sky verandah in front of every unit. It turned out that the veranda will encourage the residents for gardening, and increased planting will lower the ambient temperature. In addition to the thermal aspects, activities generated in the verandah can influence the residents to know more neighbors and have a higher sense of community.[5]

\section{CONCLUSION}

Designing middle-rise apartment with natural ventilation in warm humid tropical city in Surabaya challenge architect to create apartment that both apply passive design and maintain socio-economic aspects. These conflicting factors can be achieved by maximizing the wind flow and exploring the architectural elements which can encourage the occupant's window opening behavior, such as the design of the opening. The occupant's privacy and security also can be attained by creating different leveling, and provide social interaction space to trigger the sense of belonging in the apartment.

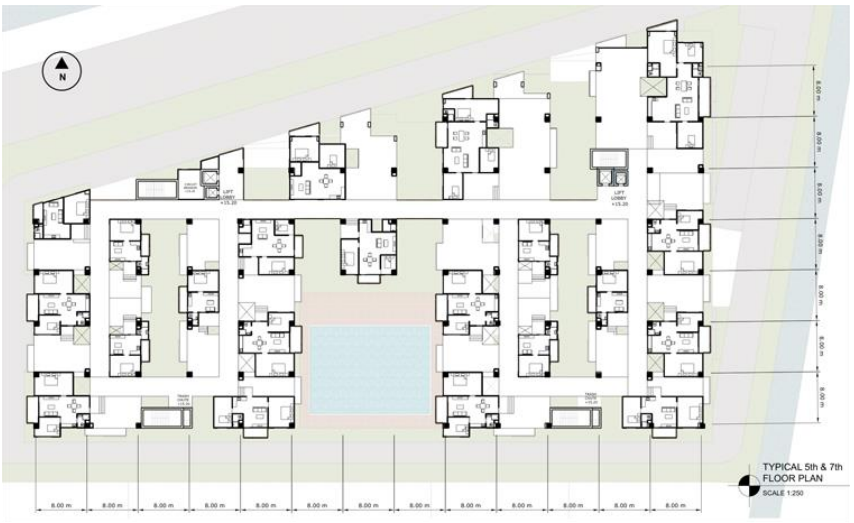

Figure 6. Typical $5^{\text {th }}$ and $7^{\text {th }}$ floor plan

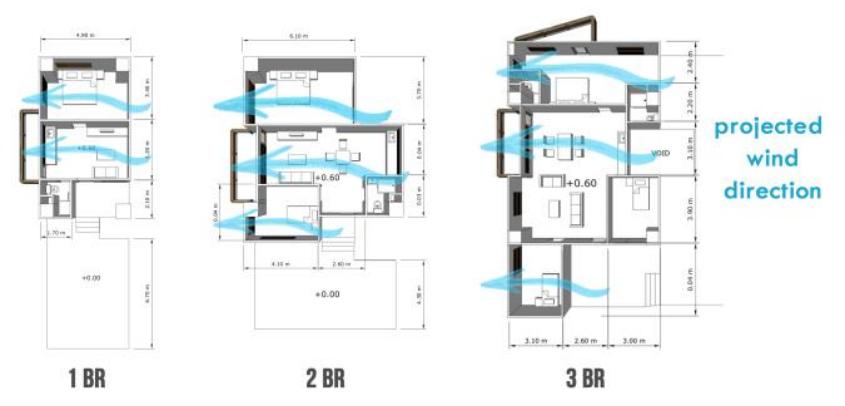

Figure 7. The Internal Room Planning Arrangement

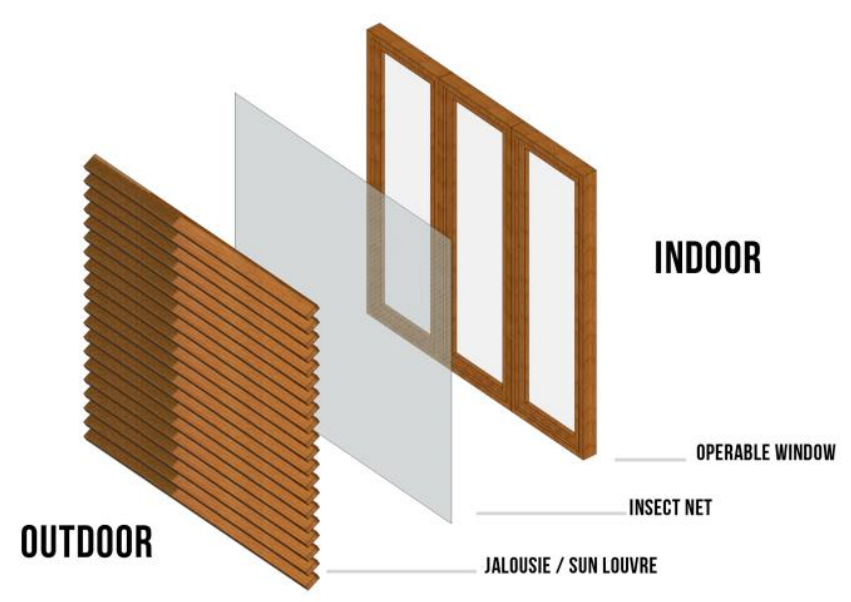

Figure 8 . The diagram of the opening system

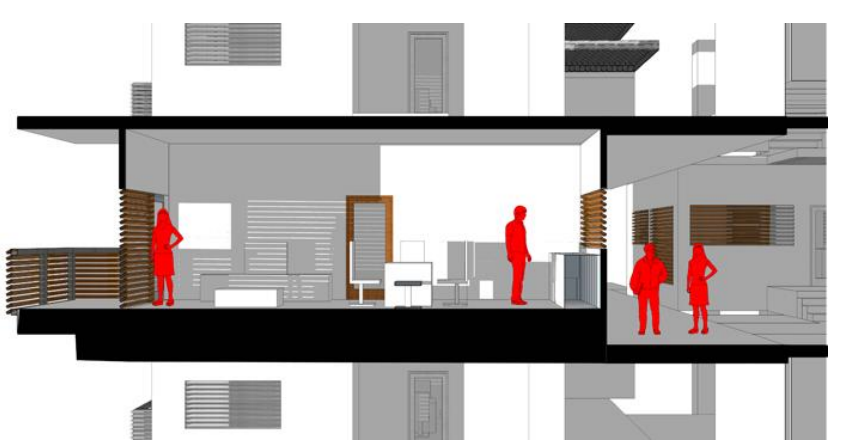

Figure 9. Section diagram of the apartement unit 


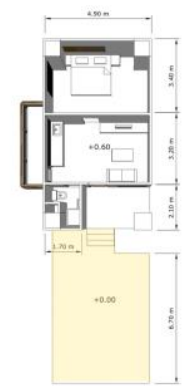

1 BR TYPE

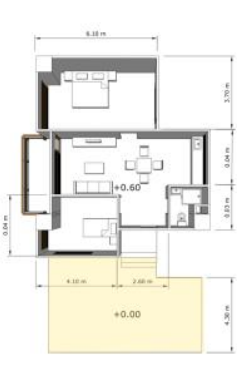

2 BR TYPE

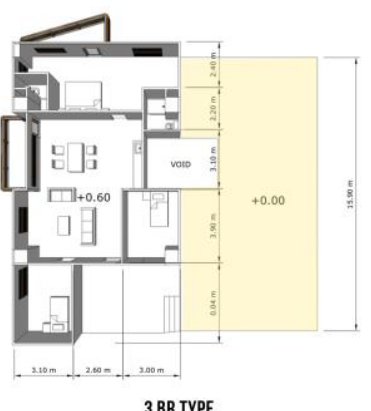

3 BR TYPE

Figure 10. The unit types and their verandah

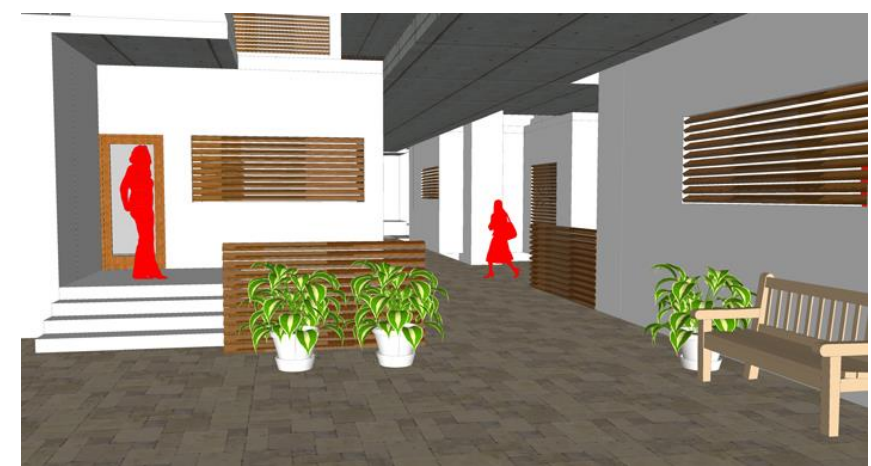

Figure 11. Perspective of unit's verandah and corridor

\section{REFERENCES}

[1] Lauber, Wolfgang, Tropical Architecture. Munich: Prestel (2005).

[2] Lechner, Nobert, Heating, Cooling, Lighting: Design Method for Architects, Canada: Wiley (2001).

[3] Arethusa, Meita Tristida, Tetsu Kubota, Agung Murti Nugroho, I Gusti Ngurah Antaryama, Sri Nastiti Ekasiwi, and Tomoko Uno, "A Field Survey of Window-Opening Behaviour and Thermal Conditions in Apartments of Surabaya, Indonesia" Intercultural Understanding. (2014) 4, 17-25.

[4] Dekay, Mark and G. Z. Brown, Sun Wind \& Light: Architectural Design Strategies, Canada: Wiley (2014).

[5] Bay, Joo-Hwa and Boon Lay Ong. Tropical Sustainable Architecture: Social and Environmental Dimensions, Oxford: Elsevier (2006). 